\title{
A State Space Modeling of Non-Isolated Bidirectional DC-DC Converter with Active Switch
}

\author{
J. Barsana Banu, M. Balasingh Moses \\ Department of Electrical and Electronics Engineering, Anna University, Trichirapalli, India \\ Email: barsanajamal@gmail.com,mosesaut@gmail.com
}

Received 9 March 2016; accepted 16 April 2016; published 19 April 2016

Copyright (C) 2016 by authors and Scientific Research Publishing Inc.

This work is licensed under the Creative Commons Attribution International License (CC BY). http://creativecommons.org/licenses/by/4.0/

(c) (i) Open Access

\begin{abstract}
In this paper, analysis, design and implementation of non-isolated soft-switching bidirectional DCDC converter with an active switch are described. The proposed topology gives the output voltage as twice as the input voltage and enhances the efficiency up to $94.5 \%$ and $92.9 \%$ for boost and buck mode operation by proper selection of the duty cycle. Soft switching can be achieved at both steps up and step down operating modes. Small signal analysis based on state space averaging and transfer functions have been presented in detail for the proposed converter. Finally, the feasibility of the desired converter is confirmed to mat lab simulation and investigational results.
\end{abstract}

\section{Keywords}

Batteries, Bidirectional Power Flow, Mathematical Analysis, Zero Current Switching, Zero Voltage Switching

\section{Introduction}

With the advancement in various industrial applications such as battery charged/discharged converters, auxiliary power supplies, fuel cell-based DC-DC converters, the renewable energy system, hybrid electric vehicles and uninterruptible power supplies system bidirectional DC-DC converters have been widely used [1]-[4]. It should be able to provide both higher and lower output voltage than the input voltage. The bidirectional DC-DC converter is mainly divided into the Isolated and Non-Isolated topology. Among the various topologies of full bridge isolated bidirectional DC-DC converter (IBDC), the transformer-based DC-DC converter is a very familiar one which comprises of two bridges separated by an isolation transformer, and it produces conduction losses due to a number of power switches. Later IBDC with the fly back and RCD snubbers, active clamp, and some 
simple auxiliary circuits are developed to improve the power conversion ratio as well as reduces voltage and current stresses, but still they need a complex control circuit separately to achieve soft start-up capability [5]-[9]. Resonant based isolated DC-DC converter also proposed to regulate voltage gain in [10] [11]. Nowadays the focus of non-isolated bidirectional DC-DC converter (NIBDC) is getting increased because of simple structure, low cost, the less number of power switches and easy control than isolated bidirectional DC-DC converter topologies [12]-[14] to achieve high efficiency. Conventional NIBDC suffers from hard switching due to power losses and electromagnetic interference which decreases the efficiency. Therefore, the diode reverse recovery problem is analyzed [15] to improve the soft switching range of bidirectional converter by appropriate selection of snubber capacitor otherwise; it causes electromagnetic interference and probability of circuit damage due to heavy current spikes. Series resonance, parallel resonance, and quasi-resonance methods have also progressed to alleviate the reverse recovery problem in the conventional NIBDC.

PWM based zero voltage transition of the bidirectional buck-boost converter is implemented to achieve high efficiency and it requires coupled inductor and the minimum of four semiconductor switches [16]. Cascading the buck and boost converter through coupled inductor is introduced [17] [18] to minimize the ripple current, but it needs more than one input source. Non-isolated DC-DC converter with voltage multiplier cell is presented to achieve soft switching in [19], but it is unsuitable for step-down operation. To overcome the above drawbacks, passive elements (inductance and Capacitance) LC series resonant tanks are connected in addition to the basic structure are proposed in [20] to achieve maximum efficiency at all load conditions. Soft-switching DC-DC converter with auxiliary switch control is proposed to improve the efficiency of the non-isolated bidirectional converter with lookup table reference [21] this method brings more efficient control in both step-up and stepdown mode operation.

In this paper, non-dissipative LCD clamp with an active switch bidirectional DC-DC converter is introduced to achieve maximum efficiency, reduces switching losses by zero voltage turn on and turn off of all semiconductor switches and applicable to high power conversion. This non-dissipative LCD snubber recycles the energy absorbed from either input or output side, and it circulates throughout the switching period. The advantages of the proposed converter topology are high reliability, simple structure, low cost and high efficiency. With these characteristics, power can be exchanged from the input voltage source to the output DC battery and vice versa happens with maximum efficiency.

This paper is ordered as follows in Section 2, the proposed converter with configuration is presented, a small signal matrix model and its transfer function are obtained in Section 2.1, simulation results have appeared in Section 3, experimental results and its discussions have appeared in Section 4.

\section{Proposed Topology}

The proposed non-isolated bidirectional DC-DC converter with an active switch in addition with passive elements is shown in Figure 1. The proposed circuit consists of two main switches $S_{1}, S_{2}$ and one active switch $S_{a}$, input side inductor $L_{m}$, Resonant inductor $L_{r}$, Snubber inductor $L_{s}$, Snubber Capacitor $C_{s}$, Resonant Capacitors $C_{r}$, and Output side Capacitor $C_{0}$, and the Diode $D_{\text {in }}$ addition with a basic bidirectional DC-DC converter topology.

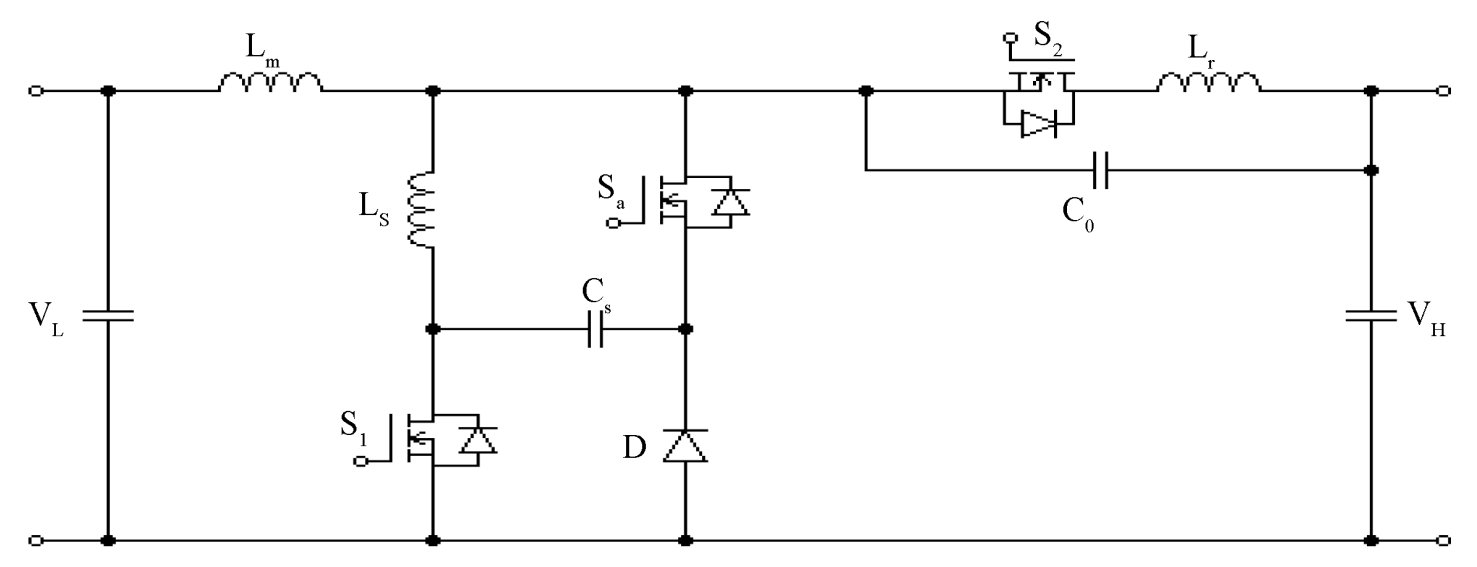

Figure 1. Proposed non-isolated topology with an active switch. 
RCD snubber is a dissipative one which dissipates a large amount of energy stored in the capacitor through the resistance. Hence, it increases the component volume and generates heat transfer troubles. The proposed nondissipative LCD clamp with passive components eliminates the above problems by storing the leakage energy into a capacitor even the power switches is in OFF condition. The active switch in the proposed topology reduces switching losses with the help of zero voltage turn on and turns off. The proposed technique is categorized into two kinds of conversion; boost mode conversion (step up) and buck mode conversion (step down) based on the current flowing through each component in a proposed circuit and voltage across the switches.

In boost mode, main switch $S_{1}$, The active switch $S_{a}$ are controlled and the anti parallel diode of $S_{2}$ operated to shift power from low voltage input side to the high voltage output side (batteries), whereas in buck mode vice versa operation takes place i.e. switches $S_{2}$ and $S_{a}$, anti parallel diode of $S_{1}$ tends to operate to exchange power from output high voltage side to the input low voltage side. Inductances $L_{m}$ and $L_{r}$ are generally used for filtering. The resonance of the proposed model is caused by the main inductor $\mathrm{Lm}$ and snubber capacitors $C_{s}$. The proposed LCD clamp to recycle the energy absorbed from either input or output side, and it circulates throughout the switching period and soft switching can be achieved. The proposed topology remains operated in continuous conduction mode during boost mode and buck mode conversion.

To intend the converter design, a theoretical investigation must be indomitable. The main aim of the steady state analysis is to obtain the transfer function of the proposed converter with the help of differential equations for various devices used in the circuit. The steady state modeling is an appropriate method that can be carried out to illustrate the relation between input and the output side of the proposed DC-DC converter with a matrix model.

The assumptions are

- Input inductor $L_{m}$ is considered as large;

- All the devices are ideal and assumed to be negligible voltage drops.

\section{Steady State Modeling}

Consider the state variables,

- Input voltage $V_{L}$

- Magnetizing Inductor current $i L_{m}$

- Resonant Inductor current $i L_{r}$

- Snubber capacitor voltage $V_{C S}$

- Output voltage $V_{C 0}$

- Duty cycles d

For simplicity, ideal assumptions are, $V_{c s}=V_{c \mathrm{r}}$ and $i L_{m}=i L_{s}$

The state space equations at state 1 (Boost Mode) are given below.

When the switch $S_{1}$ and $S_{a}$ are ON,

$$
\begin{gathered}
L_{m} \frac{\mathrm{d} i L_{m}}{\mathrm{~d} t}=v_{L} \\
L_{r} \frac{\mathrm{d} i L_{r}}{\mathrm{~d} t}=-v_{c s}-v_{c 0} \\
C_{s} \frac{\mathrm{d} v_{c s}}{\mathrm{~d} t}=i L_{r} \\
C_{0} \frac{\mathrm{d} v_{c o}}{\mathrm{~d} t}=i L_{r}-\frac{v_{c o}}{R_{0}}
\end{gathered}
$$

When switch $S_{1}$ is OFF,

$$
\begin{gathered}
L_{m} \frac{\mathrm{di} L_{m}}{\mathrm{~d} t}=-v_{c s}+v_{L} \\
L_{r} \frac{\mathrm{d} i L_{r}}{\mathrm{~d} t}=-v_{c 0}
\end{gathered}
$$




$$
\begin{gathered}
C_{s} \frac{\mathrm{d} v_{c s}}{\mathrm{~d} t}=i L_{m} \\
C_{0} \frac{\mathrm{d} v_{c o}}{\mathrm{~d} t}=i L_{r}-\frac{v_{c o}}{R_{0}}
\end{gathered}
$$

Applying the state-space averaging method for the above Equations (1)-(8), state equations become over a switching cycle.

$$
\begin{gathered}
L_{m} \frac{\mathrm{d} i L_{m}}{\mathrm{~d} t}=-(1-d) v_{c s}+v_{L} \\
L_{r} \frac{\mathrm{d} i L_{r}}{\mathrm{~d} t}=d v_{c s}-v_{c 0} \\
C_{s} \frac{\mathrm{d} v_{c s}}{\mathrm{~d} t}=(1-d) i L_{m}-d i L_{r} \\
C_{0} \frac{\mathrm{d} v_{c o}}{\mathrm{~d} t}=i L_{r}-\frac{v_{c o}}{R_{0}}
\end{gathered}
$$

Next, Introducing perturbation in state variables such that

$$
\begin{gathered}
i L_{m}=I L_{m}+\overline{i L_{m}}, i L_{r}=I L_{r}+\overline{i L_{r}} \\
v_{c s}=V_{c s}+\overline{v_{c s}}, \quad v_{c 0}=V_{c 0}+\overline{v_{c 0}} \\
v_{L}=V_{L}+\overline{v_{L}}, d=D+\bar{d}
\end{gathered}
$$

where $\bar{d}$ is a small AC variation in duty ratio, $\overline{i L_{m}}$ And $\overline{i L_{r}}$ are small AC variations in magnetizing iductor current and resonant Inductor current. Similarly, $\overline{v_{c s}}$ and $\overline{v_{c 0}}$ are small AC variations in snubber capacitor and output voltage.

$$
\begin{gathered}
L_{m} \frac{\mathrm{d}\left(i I L_{m}+\overline{i L_{m}}\right)}{\mathrm{d} t}=-(1-D-\bar{d})\left(V_{c s}+\overline{V_{c s}}\right)+\left(V_{L}+\overline{v_{L}}\right) \\
L_{r} \frac{\mathrm{d}\left(I L_{r}+\overline{i L_{r}}\right)}{\mathrm{d} t}=(D+\bar{d})\left(V_{c s}+\overline{v_{c s}}\right)-\left(V_{c 0}+\overline{v_{c 0}}\right) \\
C_{s} \frac{\mathrm{d}\left(V_{c s}+\overline{v_{c s}}\right)}{\mathrm{d} t}=(1-D-\bar{d})\left(I L_{m}+\overline{i L_{m}}\right)-d\left(I L_{r}+\overline{i L_{r}}\right) \\
C_{0} \frac{\mathrm{d}\left(V_{c 0}+\overline{v_{c 0}}\right)}{\mathrm{d} t}=\left(I L_{r}+\overline{i L_{r}}\right)-\frac{\left(V_{c 0}+\overline{v_{c 0}}\right)}{R_{0}}
\end{gathered}
$$

Equate AC and DC quantities for Equations (13)-(16). Consider AC quantity only for small signal analysis, DC quantities in the above Equations (13)-(16) are neglected.

$$
\begin{gathered}
L_{m} \frac{\mathrm{d} \overline{i L_{m}}}{\mathrm{~d} t}=-(1-D) \overline{v_{c s}}+V_{c s} \bar{d}+\overline{v_{L}} \\
L_{r} \frac{\mathrm{d} \overline{i L_{r}}}{\mathrm{~d} t}=D \overline{v_{c s}}+V_{c s} \bar{d}-\overline{v_{c 0}} \\
C_{s} \frac{\mathrm{d} \overline{\nu_{c s}}}{\mathrm{~d} t}=(1-D) \overline{i L_{m}}-I L_{m} \bar{d}-I L_{r} \bar{d}-D \overline{i L_{r}} \\
C_{0} \frac{\mathrm{d} \overline{\nu_{c 0}}}{\mathrm{~d} t}=\bar{i} \bar{L}_{r}-\frac{\overline{v_{c 0}}}{R_{0}}
\end{gathered}
$$


The output transfer function can be obtained either by building and simplified the linearized block diagram or by the matrix model. For constructing a matrix-Small signal model, the Equations (17)-(20) are arranged in symmetrical sequence after taking Laplace transformation. In matrix form, the equations can be written as,

$$
\begin{aligned}
& {\left[\begin{array}{cccc}
S c_{s} & 0 & -(1-D) & D \\
0 & S c_{0}+\frac{1}{R_{0}} & 0 & -1 \\
(1-D) & 0 & S L_{m} & 0 \\
-D & 1 & 0 & S L_{r}
\end{array}\right]\left[\begin{array}{l}
\overline{v_{c s}} \\
\frac{v_{c 0}}{i L_{m}} \\
i L_{r}
\end{array}\right]=\left[\begin{array}{c}
-\left(I L_{m}+I L_{r}\right) \\
0 \\
V_{c s} \\
V_{c s}
\end{array}\right] \overline{d(s)}+\left[\begin{array}{l}
0 \\
0 \\
1 \\
0
\end{array}\right] \overline{v_{L}(s)}} \\
& \frac{\overline{v_{c 0}(s)}}{\overline{d(s)}}=\frac{\left[\frac{C_{s} L_{m} v_{c s}}{(1-D)^{2}}\right] S^{2}-\frac{D L_{m}}{(1-D)^{2}}\left(I L_{m}+I L_{r}\right) S+\frac{v_{c s}}{1-D}}{\left[\frac{C_{s} C_{0} L_{m} L_{r}}{(1-D)^{2}}\right] S^{4}+\left[\frac{C_{s} L_{m} L_{r}}{R_{0}(1-D)^{2}}\right] S^{3}+\left[\frac{C_{s} L_{m}}{(1-D)^{2}}+C_{0}\left(\frac{D^{2}}{(1-D)^{2}} L_{m}+L_{r}\right)\right] S^{2}+\left[\frac{L_{r}}{R_{0}}+\frac{L_{m} D^{2}}{R_{0}(1-D)^{2}}\right] S+1}
\end{aligned}
$$

From Equation (21) inverse matrix can be determined to obtain a control output converter transfer function. The Equation (22) represents the steady state control (duty cycle) to output transfer function of the proposed NIBDC converter boost mode. Similarly, control to output current transfer function derived for buck mode. Bode plot for the derived transfer function for boost and buck modes are shown in Figure 2 and Figure 3.

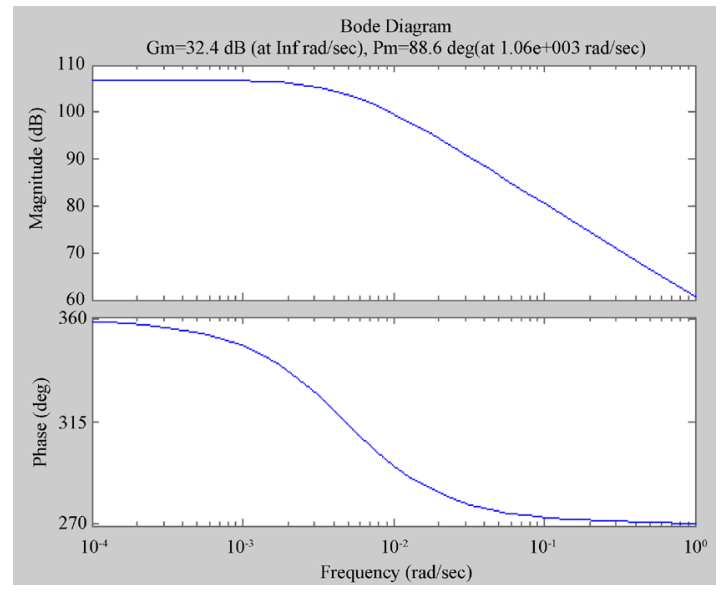

Figure 2. Proposed control to output bode plot-boost mode.

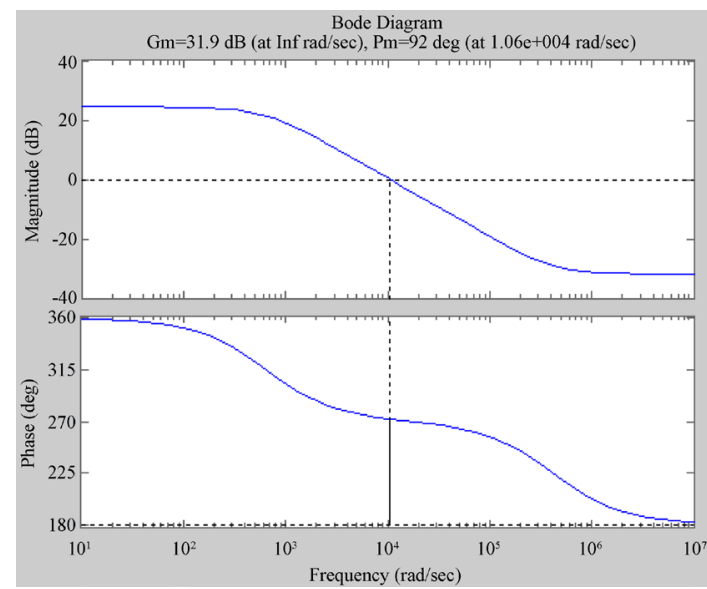

Figure 3. Proposed control to output bode plot-buck mode. 


\section{Simulation Results}

The whole circuit is simulated using MATLAB software and following the results is obtained for the proposed non isolated bidirectional DC-DC converter with active switch during boost and buck modes. Then the results obtain from the proposed topology is compared with the conventional simple non isolated bidirectional DC-DC converter without any additional switch and auxiliary circuits to verify its feasibility.

Figure 4 shows the input ( $50 \mathrm{~V}$ ) and output voltage for the boost conversion. It is evident that the output voltage obtained is twice than the given input. Gate pulse, current flow through and voltages across the main switch $S_{1}$ are shown in Figure 5. It is clearly noticed that switch $S_{1}$ are turned on and off at zero voltage. Input and output voltage for buck mode is illustrated in Figure 6.

Similarly, the voltage across $S_{2}$ and the current through it in buck mode is observed in Figure 7. So switching losses in the conventional NIBDC is eliminated. Therefore, the proposed NIBDC improves the efficiency by $>5 \%$ from the conventional converter in boost and buck modes.

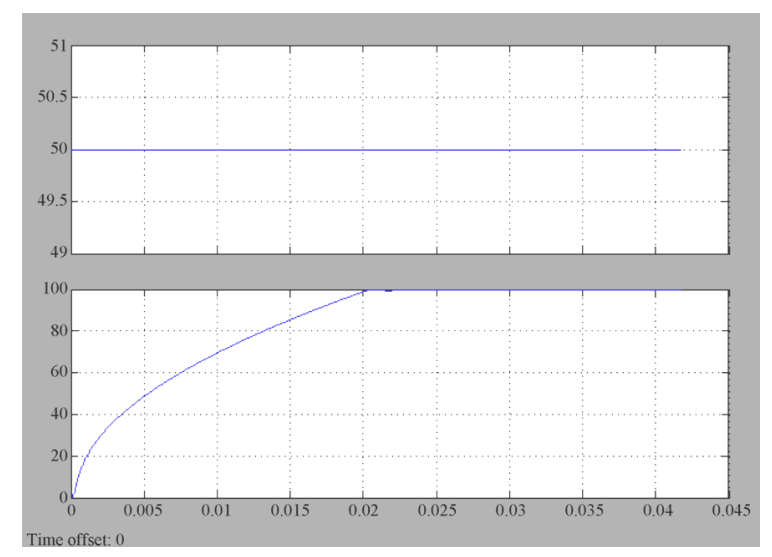

Figure 4. Input and output voltage for boost mode.

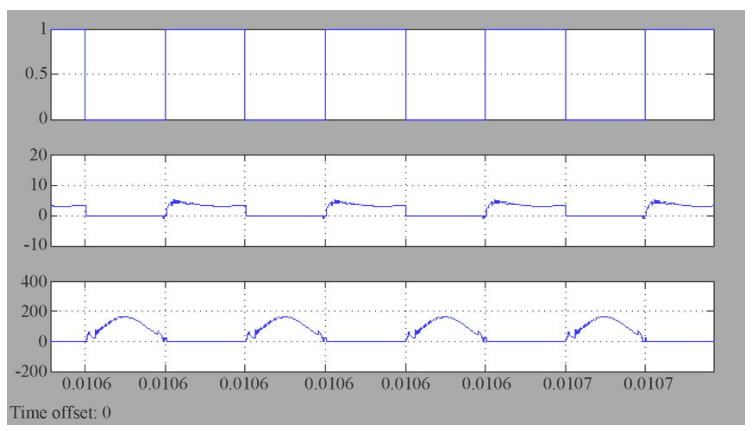

Figure 5. Triggering pulse, current through and voltage across switch $S_{1}$.

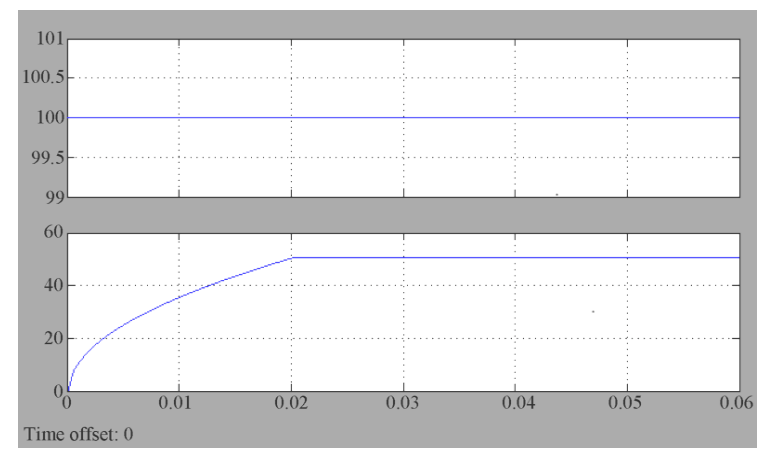

Figure 6. Input and output voltage for buck mode. 


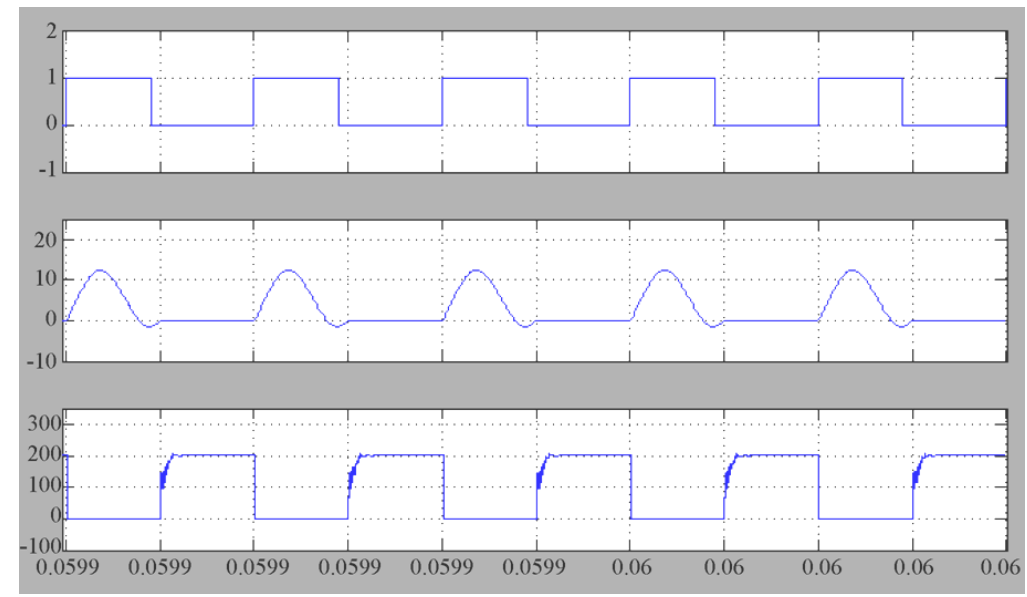

Figure 7. Triggering pulse, current through and voltage across switch $S_{2}$.

\section{Comparative Results}

Figure 8 and Figure 9 illustrate the efficiency comparison of the boost and buck mode with a conventional converter that is a simple non isolated bidirectional DC-DC converter for various input voltages. Which implies the proposed topology achieves high efficiency nearly from $86.2 \%$ to $94.4 \%$ for boost conversion and for buck mode it improves from $86.6 \%$ to $92.9 \%$ successfully. Similarly, the output power comparison of boost and buck mode is done in Figure 10 and Figure 11, which shows that proposed topology gives more output power than conventional NIBDC for the same input voltages given.

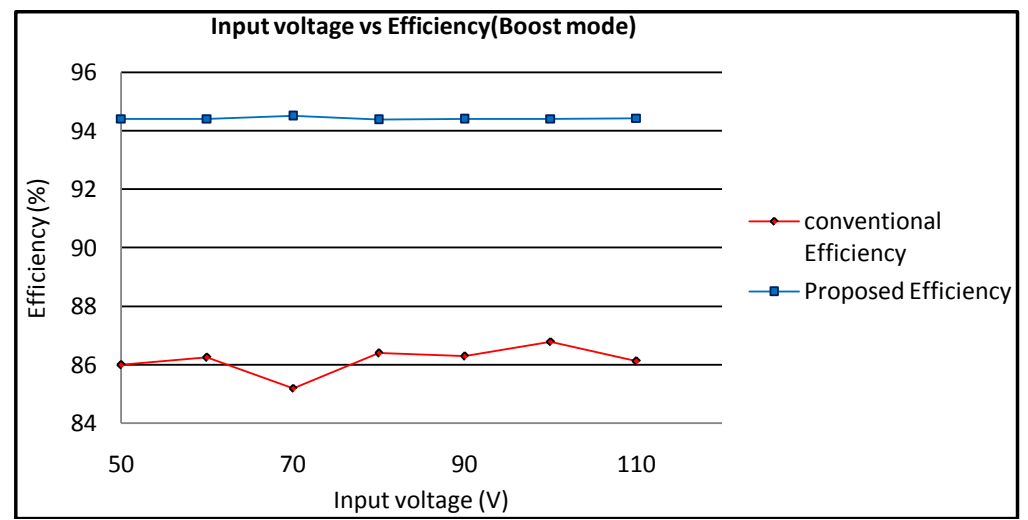

Figure 8. Efficiency comparison of boost mode.

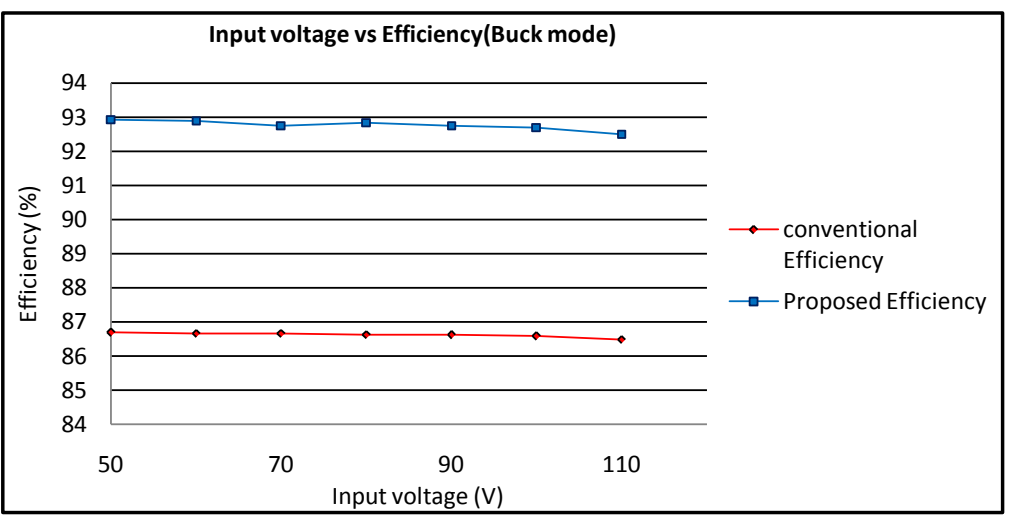

Figure 9. Efficiency comparison of buck mode. 


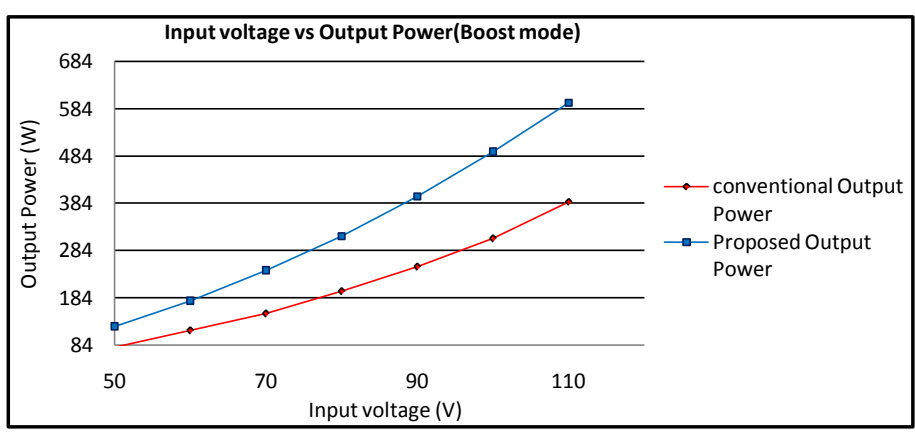

Figure 10. Output power comparison of boost mode.

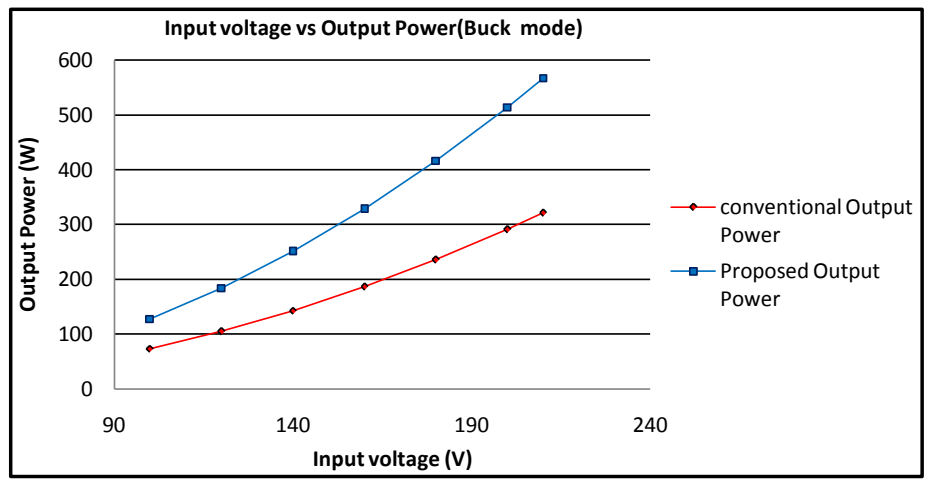

Figure 11. Output power comparison of buck mode.

\section{Hardware Results and Discussion}

In order to confirms the feasibility of the proposed topology. A $0.5 \mathrm{KW}$ converter model was built and implemented with PIC Microcontroller and driver circuits to obtain the same results as discussed in Section 3. The experimental setup is depicted in Figure 12.

The input voltage of the given prototype for boost mode is $50 \mathrm{~V}$ and obtains $100 \mathrm{~V}$ as output it is twice than the given input voltage and vice versa for buck mode is observed. The operating power of the converter is 500 $\mathrm{W}$ and its switching frequency is considered as $100 \mathrm{kHz}$. For all the three power switches $S_{1}, S_{2}$ and $S_{a}$ IRF840 are employed and IN 4007 diode is used. $L_{r}$ and $C_{r}$ are designed as $40 \mu \mathrm{H}$ and $80 \mathrm{nF}$. $L_{m}$ and $L_{s}$ values are 450 $\mu \mathrm{H}$ and $4 \mu \mathrm{H}$ respectively. The values of $C_{s}$ and $C_{0}$ are $18 \mathrm{nF}$ and $47 \mu \mathrm{F}$. The switching pulse and voltage waveforms for both the buck and boost modes are measured. The gate pulse and voltage across the switches are also observed to verify its effectiveness.

The triggering pulses for the boost mode switch $S_{1}$ and active switch $S_{a}$ is observed in Figure 13. During boost conversion $S_{2}$ remains OFF state. The switching pulse and zero crossing voltage across the switches $S_{1}$ and $S_{2}$ are indicated in Figure 14 and Figure 16. It is noted that switches are turned ON and OFF at zero voltage. The triggering pulses for the buck mode switch $S_{2}$ and active switch $S_{a}$ is measured in Figure 15.

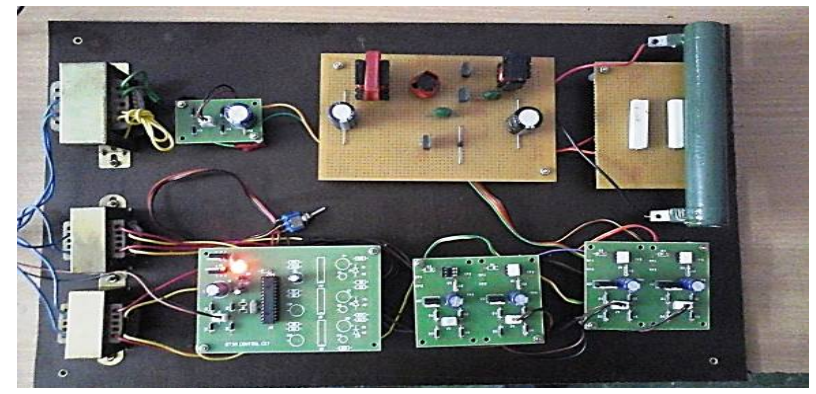

Figure 12. Experimental set up. 


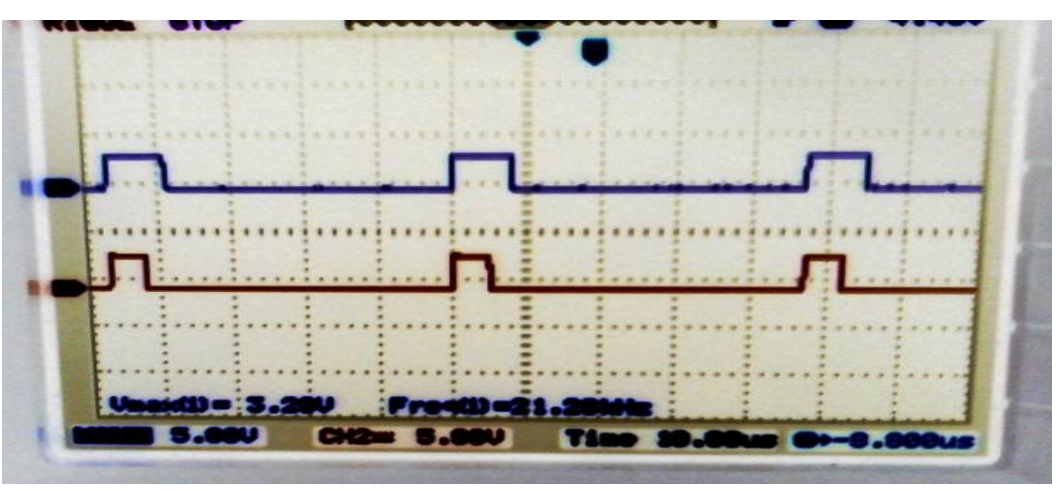

Figure 13. Triggering pulses for $S_{1}$ and $S_{a}$ during boost mode.

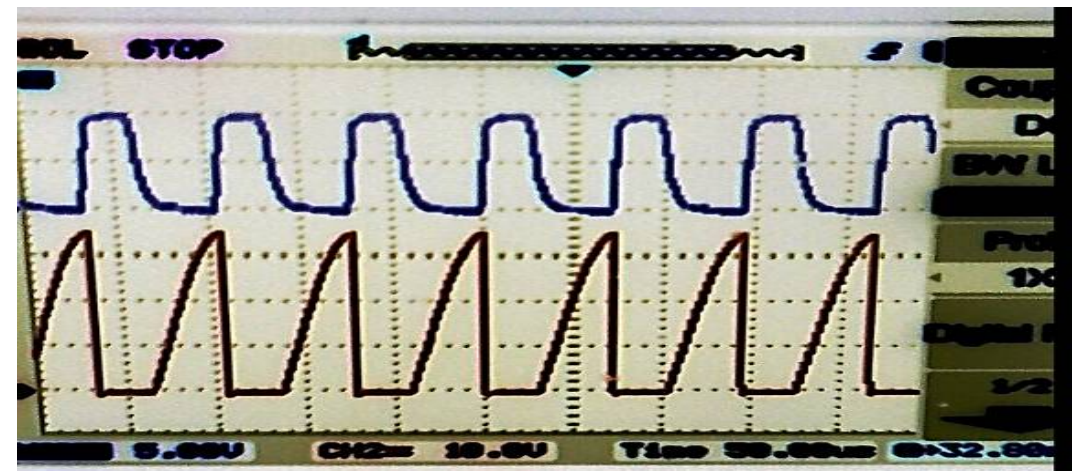

Figure 14. Experimental results of the switching pulse and voltage across $S_{1}$ of the proposed boost mode.

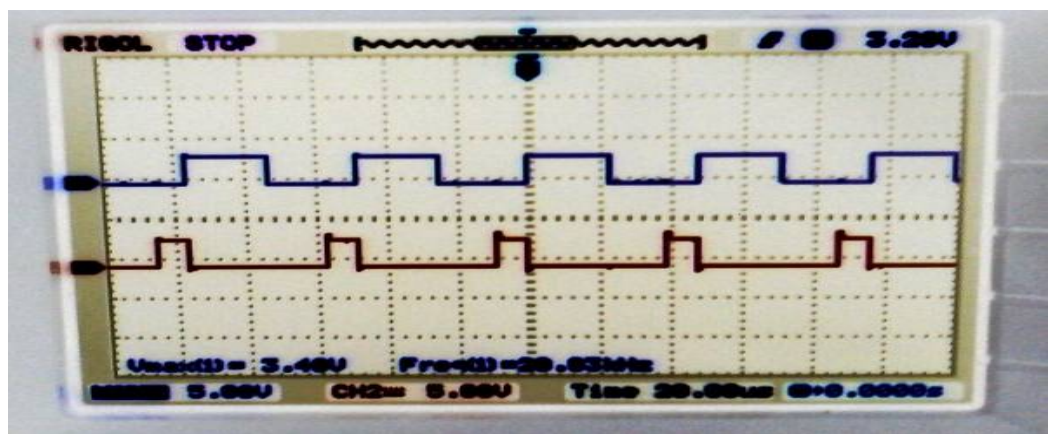

Figure 15. Triggering pulses for $S_{2}$ and $S_{a}$ during buck mode.

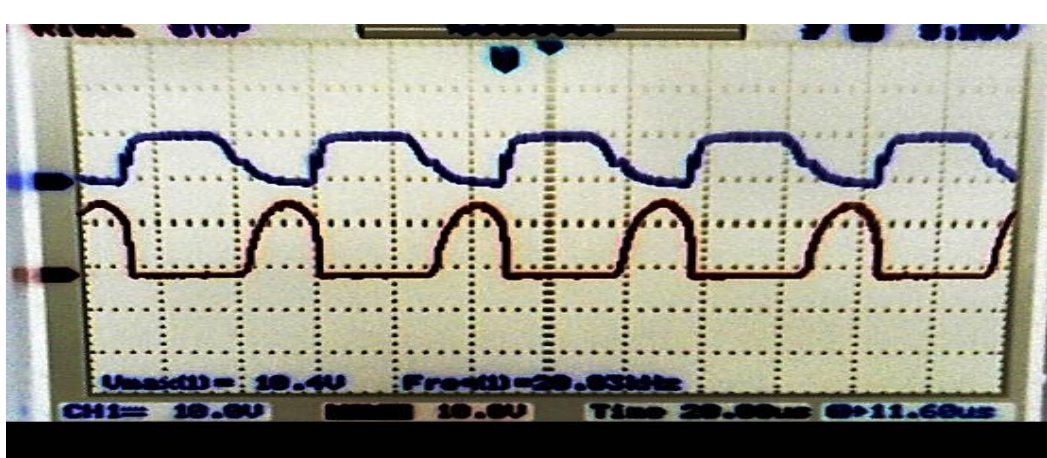

Figure 16. Experimental results of the switching pulse and voltage across $S_{2}$ of the proposed buck mode. 


\section{Conclusion}

In this paper, non-isolated bidirectional DC-DC converter with active switch suitable for battery charging/discharging application is proposed with high efficiency up to $94.5 \%$ and $92.9 \%$ for boost and buck mode operation as compared to conventional topologies. The proposed topology is analyzed by state-space averaging technique and its transfer function is derived. The zero voltage turns on and turns off, and the switches are obtained in simulation and experimental waveforms. From the above results, the performance of the proposed converter with active switch achieves higher efficiency than the conventional NIBDC is verified.

\section{References}

[1] Aharon, I., Kuperman, A. and Shmilovitz, D. (2013) Analysis of Bi-Directional Buck-Boost Converter for Energy Storage Applications. 39th Annual Conference of the IEEE Industrial Electronics Society, Vienna, 10-13 November 2013, 858-863. http://dx.doi.org/10.1109/iecon.2013.6699246

[2] Peng, F.Z., Li, H., Su, G.J. and Lawler, J.S. (2004) A New ZVS Bidirectional DC-DC Converter for Fuel Cell and Battery Application. Industrial Electronics Society, 19, 54-65. http://dx.doi.org/10.1109/TPEL.2003.820550

[3] Adib, E. and Farzanehfard, H. (2009) Soft Switching Bidirectional DC-DC Converter for Ultracapacitor-Batteries Interface. Energy Conversion and Management, 50, 2879-2884. http://dx.doi.org/10.1016/j.enconman.2009.07.001

[4] Acik, A. and Cadirci, I. (2002) Active Clamped ZVS Forward Converter with Soft-Switched Synchronous Rectifier. Turkish Journal of Electrical Engineering \& Computer Sciences, 10, 473-491.

[5] Wu, T.-F., Chen, Y.-C., Yang, J.-G. and Kuo, C.-L.(2010) Isolated Bidirectional Full-Bridge DC-DC Converter with a Flyback Snubber. IEEE Transactions on Power Electronics, 25, 1915-1922. http://dx.doi.org/10.1109/TPEL.2010.2043542

[6] Lee, Y.-C. (2014) A Study on Implementing a Phase-Shift Full-Bridge Converter Employing an Asynchronous Active Clamp Circuit. Journal of Power Electronics, 14, 413-420. http://dx.doi.org/10.6113/JPE.2014.14.3.413

[7] Wu, T.-F., Yang, J.-G., Kuo, C.-L., Sun, K.-H. and Chen, Y.-K. (2011) Comparison of Bi-Directional Isolated FullBridge Converters with Combinations of Active and Passive Snubbers. IEEE Energy Conversion Congress and Exposition, Phoenix, 17-22 September 2011, 127-133.

[8] Gorla, N.B.Y. and Lakshmi Narasamma, N. (2014) A New Active Soft Switching Technique for Pulse Width Modulated Full Bridge DC-DC Converters. International Journal of Environmental Science and Development, 5, 20-25.

[9] Barsana Banu, J. and Balasingh Moses, M. (2014) A New Isolated Bidirectional Full Bridge DC-DC Converter with Auxiliary Circuit. International Journal of Applied Engineering research, 9, 8056-8064.

[10] Yang, S., Abe, S., Zaitsu, T., Yamamoto, J., Shoyama, M. and Ninomiya, T. (2012) Consideration of Operating Characteristics for Bi-Directional LLC Resonant Converter. International Journal of Renewable Energy Research, 12, 790796.

[11] Jalbrzykowski, S. and Citko, T. (2013) Push-Pull Resonant DC-DC Isolated Converter. Bulletin of the Polish Academy of Sciences Technical Sciences, 61, 763-769. http://dx.doi.org/10.2478/bpasts-2013-0082

[12] Baburaja, C. and Jayakumar, J. (2013) Transformer Less Soft Switching Bi-Directional DC-DC Chopper. International journal of Engineering and Advanced Technology, 2, 391-395.

[13] Prasad, H., Maity, T. and Singh, V.K. (2014) A Simple Transformerless Buck-Boost Switching Voltage Regulator. Asian Power Electronics Journal, 8, 57-61.

[14] Shahin, A., Huang, B., Martin, J.P., Pierfederici, S. and Davat, B. (2010) New Non-Linear Control Strategy for NonIsolated DC/DC Converter with High Voltage Ratio. Energy Conversion and Management, 51, 56-63. http://dx.doi.org/10.1016/j.enconman.2009.08.032

[15] Mohammadi, M.R. and Farzanehfard, H. (2015) Analysis of Diode Reverse Recovery Effect on the Improvement of Soft-Switching Range in Zero-Voltage-Transition Bidirectional Converters. IEEE Transactions on Industrial Electronics, 62, 1471-1479. http://dx.doi.org/10.1109/TIE.2014.2363425

[16] Mirzaei, A., Jusoh, A. and Salam, Z. (2012) Design and Implementation of High Efficiency Non-Isolated Bidirectional Zero Voltage Transition Pulse Width Modulated DC-DC Converters. Energy, 47, 358-369. http://dx.doi.org/10.1016/j.energy.2012.09.035

[17] Zhang, J.J., Xing, Y., Wu, H.F., Sun, K. and Cao, F. (2015) A Novel Dual-Input Boost-Buck Converter with Coupled Inductors for Distributed Thermoelectric Generation Systems. Journal of Power Electronics, 15, 899-909. http://dx.doi.org/10.6113/JPE.2015.15.4.899

[18] Ji, B.J., Wang, J.H., Hong, F. and Huang, S.M. (2015) A Family of Non-Isolated Photovoltaic Grid Connected Inverters without Leakage Current Issues. Journal of Power Electronics, 15, 920-928. http://dx.doi.org/10.6113/JPE.2015.15.4.920 
[19] Mahalingam, P. (2014) Soft Switched Voltage Multiplier Cell Based DC-DC Converter for Automotive Applications. Automatika, 55, 239-245.

[20] Jung, D.-Y., Hwang, S.-H., Ji, Y.-H., Lee, J.-H., Jung, Y.-C. and Won, C.-Y. (2013) Soft-Switching Bidirectional DC/DC Converter with a LC Series Resonant Circuit. IEEE Transactions on Power Electronics, 28, 1680-1690. http://dx.doi.org/10.1109/TPEL.2012.2208765

[21] Lee, J.-H., Yu, D.-H., Kim, J.-G. and Kim, Y.-H. (2013) Auxiliary Switch Control of a Bidirectional Soft Switching DC-DC Converter. IEEE Transactions on Power Electronics, 28, 5446-5457. http://dx.doi.org/10.1109/TPEL.2013.2254131 